\title{
Ion Chromatography Analysis of Dibutyl Phosphoric Acid
}

by

R. J. Ray

Westinghouse Savannah River Company

Savannah River Site

Aiken, South Carolina 29808

This paper was prepared in connection with work done under the above contract number with the U.S. Department of Energy. By acceptance of this paper, the publisher and/or recipient acknowledges the U.S. Government's right to retain a nonexclusive, royalty-free license in and to any copyright covering this paper, along with the right to reproduce and to authorize others to reproduce all or part of the copyrighted paper. 


\section{DISCLAIMER}

This report was prepared as an account of work sponsored by an agency of the United States Government. Neither the United States Government nor any agency thereof, nor any of their employees, makes any warranty, express or implied, or assumes any legal liability or responsibility for the accuracy, completeness, or usefulness of any information, apparatus, product, or process disclosed, or represents that its use would not infringe privately owned rights. Reference herein to any specific commercial product, process, or service by trade name, trademark, manufacturer, or otherwise does not necessarily constitute or imply its endorsement, recommendation, or favoring by the United States Government or any agency thereof. The views and opinions of authors expressed herein do not necessarily state or reflect those of the United States Government or any agency thereof.

This report has been reproduced directly from the best available copy.

Available to DOE and DOE contractors from the Office of Scientific and Technical Information, P. O. Box 62, Oak Ridge, TN 37831; prices available from (423) 576-8401.

Available to the public from the National Technical Information Service, U. S. Department of Commerce, 5285 Port Royal Road, Springfield, VA 22161. 


\section{DISCLAIMER}

Portions of this document may be illegible in electronic image products. Images are produced from the best available original document. 


\section{Ion Chromatography Analysis of Dibutyl Phosphoric Acid}

\section{R.J. Ray}

Analytical Development Section - Savannah River Technology Center, Westinghouse Savannah River Company, Aiken, SC

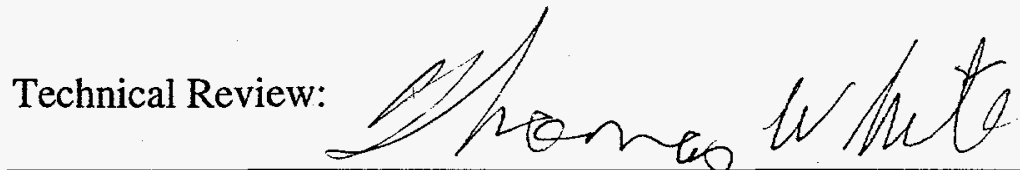

T. White

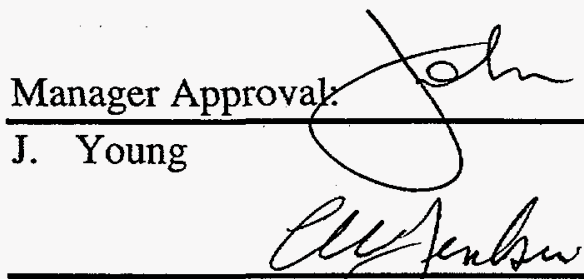

Authorized Derivative lassifier
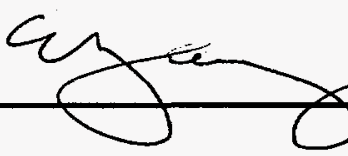

[
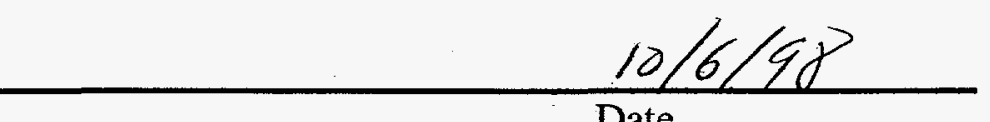


\begin{abstract}
Analysis of dibutyl phosphate (DBP), a degradation product of tributyl phosphate (TBP), has long been a problem analysis by Ion Chromatography at the Savannah River Site. Due to the presence of $\mathrm{UO}_{2}{ }^{+2}$ and high $\mathrm{NO}_{3}^{-1}$ concentrations, inadequate recovery and separation of DBP on the chromatographic column had rendered the analysis undependable and very inconsistent, thus causing high uncertainties in the data.

The method presented here by the Savannah River Technology Center (SRTC)/Analytical Development Section (ADS) addresses the sample preparation problems encountered when analyzing for DBP in the presence of uranium and nitrate. The data presented reflects the improvements made to decrease data uncertainty and increase data accuracy and precision.
\end{abstract}

\title{
Introduction
}

The Savannah River Site has enriched uranium (EU) solutions that have been stored for the past 10 years since being purified in the Plutonium-Uranium Extraction Process (PUREX). Residual tributyl phosphate in these solutions has slowly hydrolyzed to form uranium dibutyl phosphate complexes which have limited solubility. ${ }^{1}$ The potential to form $\mathrm{UO}_{2}(\mathrm{DBP})_{2}$ precipitates raises criticality safety concerns; therefore, the concentration of DBP must be measured accurately and precisely.

Ion Chromatography (IC) is a viable and cost-effective method of analyzing for the presence of DBP. This paper describes the calibration curve, sample matrix, and sample preparation associated with DBP analysis. In summary, DBP is extracted from an aqueous matrix containing $15 \mathrm{~g} / \mathrm{L}$ uranium and $0.15 \underline{\mathrm{M}}$ nitrate into 2 -ethyl hexanol, back extracted into $1 \underline{\mathrm{M}}$ sodium hydroxide, filtered to remove sodium interferent, and analyzed by $\mathrm{IC}$. The statistical data describes the method detection limit and the accuracy/precision of this method.

\section{Experimental}

Standard solutions of DBP (not containing uranium) were prepared using a 97\% reagent standard from Aldrich Chemical Company. A $100 \mathrm{~mL}$ standard stock solution was prepared at $1000 \mu \mathrm{g} / \mathrm{mL}$ using $25 \mathrm{~mL}$ of HPLC grade methanol to dissolve DBP into solution with water. Calibration standards were prepared from this stock solution at $10 \mu \mathrm{g} / \mathrm{mL}, 50 \mu \mathrm{g} / \mathrm{mL}$, and $100 \mu \mathrm{g} / \mathrm{mL}$. The linearity of this 3-point calibration curve had a relative standard deviation (RSD) of $10 \%$. Figure 1 shows the stability of DBP in $75 \%$ water and $25 \%$ methanol, in the presence of light. Figure 2 shows the linearity of the calibration curve.

\footnotetext{
${ }^{1}$ Bob Pierce, Major Thompson, Robert Ray. WSRC-TR-98-00188, Rev. 0.
} 
Fig. 1 Stability of $D B P(10 \mu \mathrm{g} / \mathrm{mL})$ in $75: 25$ Water/Methanol over time

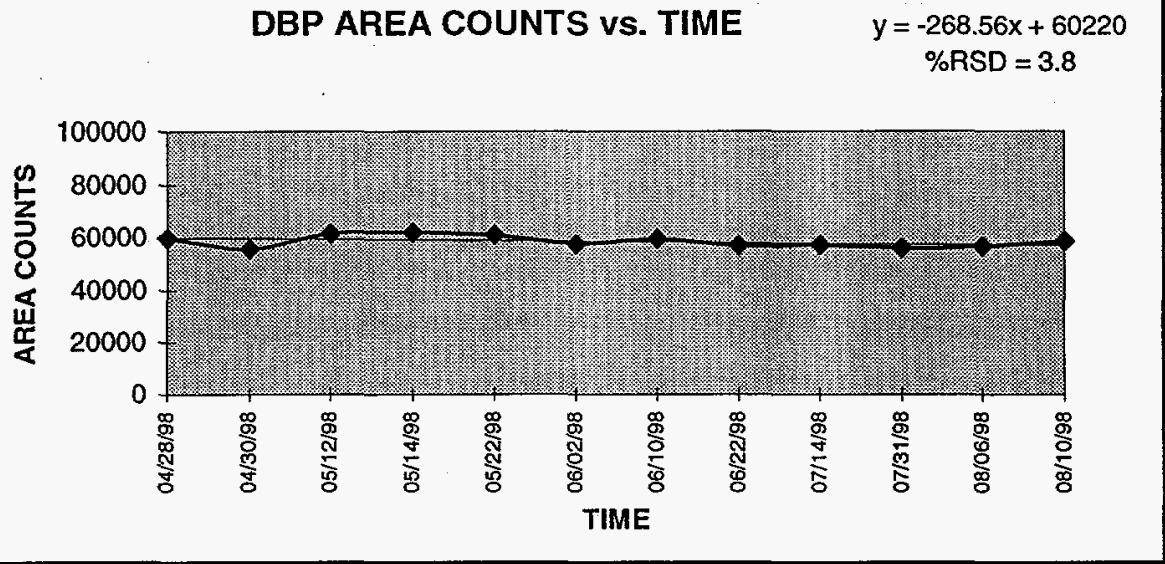

As evidenced in Figure 1, the daily calibration verification standard is very stable as a function of time. There is minimal degradation. The standard prep by the technician is very reproducible. Moreover, the analytical system has a very stable response to DBP as a function of time. This stability is the basis for reproducible measurements performed by Ion Chromatography.

The calibration curve shown in Figure 2 is a plot of detector response over concentration. Detector linearity is demonstrated by a relative standard deviation of $15 \%$ or less. ${ }^{2}$ Figure 2 also illustrates the capacity of the conductivity detector for a wide range of linearity. A wide range of linearity is useful when analyzing samples which have wide ranges of DBP concentrations. However, most of the samples we have analyzed thus far range between $0.2 \mu \mathrm{g}$ and $1 \mu \mathrm{g} \mathrm{DBP}$ on column, dilution factor not accounted for. Therefore, a calibration range between $0.2 \mu \mathrm{g}$ and $2 \mu \mathrm{g}$ DBP on column can serve as a practical calibration curve.

Figure 2. Detector Response Over a Wide Concentration Range

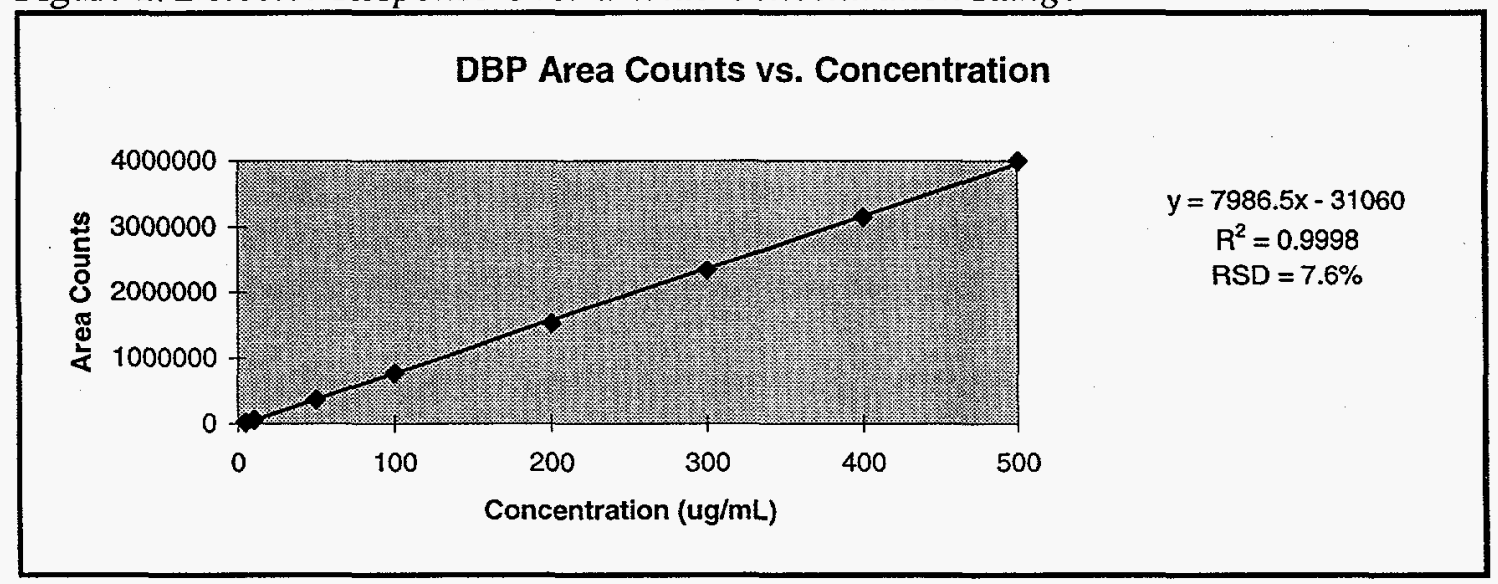

\footnotetext{
${ }^{2}$ EPA, 1990. SW-846, Method 8000.
} 
Linearity and sensitivity decreases significantly below the $10 \mu \mathrm{g} / \mathrm{mL}(0.2 \mu \mathrm{g}$ on column). See Figure 3 for illustration. The response factor of the $10 \mu \mathrm{g} / \mathrm{mL} \mathrm{DBP}$ standard may be used to quantify samples that have DBP concentrations between $2 \mu \mathrm{g} / \mathrm{mL}$ and $10 \mu \mathrm{g} / \mathrm{mL}$, dilution factor not included. The relative standard deviation between $0.04 \mu \mathrm{g}$ and $0.2 \mu \mathrm{g}$ DBP on column was $14 \%$.

Figure 3. Line Plot of Detector Response

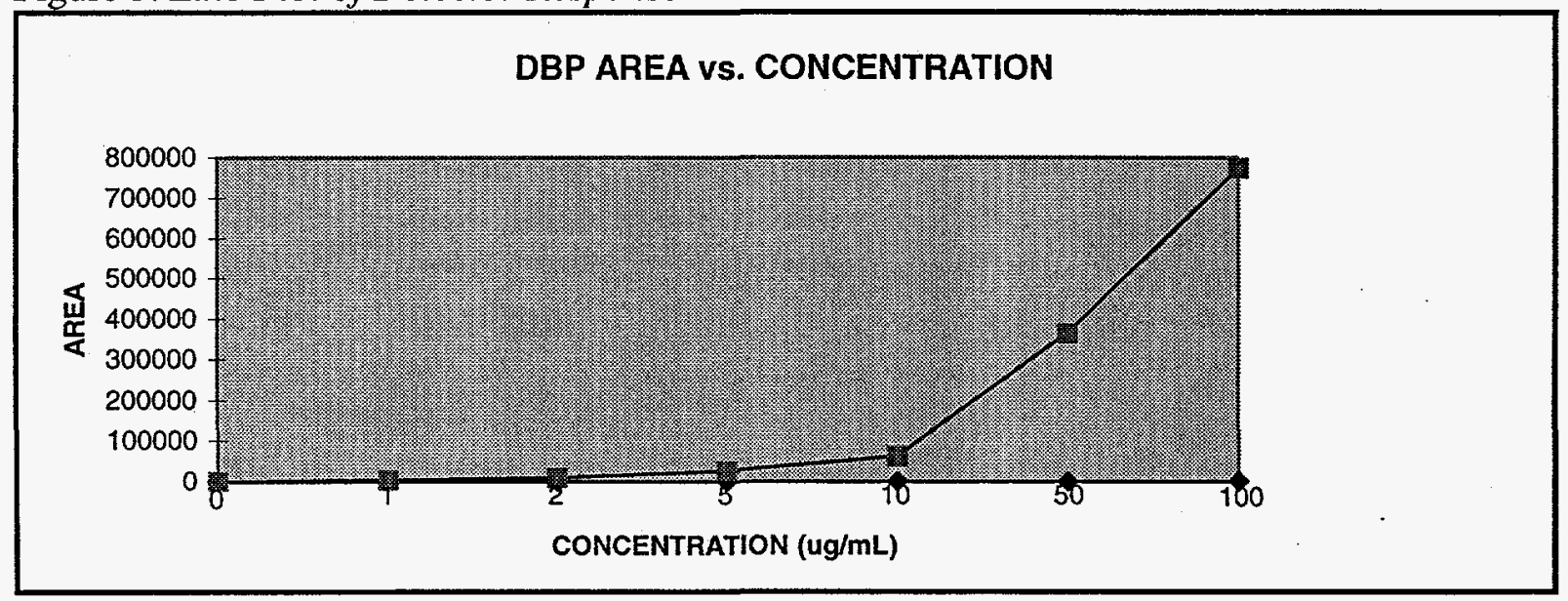

The IC system consists of a Dionex gradient pump (DX-300), conductivity detector (CDM-I), and an anion self-regenerating suppressor (ASRS II). The analytical columns were two AS4A columns (4mm ID) connected in series. The guard column was an AG4 (4mm ID). The eluent was a mixture of sodium carbonate/sodium bicarbonate at $0.225 \mathrm{mM}$ respectively. Flow rate was $1.2 \mathrm{~mL} / \mathrm{min}$. A $20 \mu \mathrm{L}$ sample loop was used for all injections.

A $1 \mathrm{~mL}$ aliquot of the matrix material $(15 \mathrm{~g} / \mathrm{L}$ uranium and $0.15 \underline{\mathrm{M}}$ nitrate $)$ was added to a $22 \mathrm{~mL}$ glass vial containing $5 \mathrm{~mL}$ of milli-Q water. The contents were spiked with $20 \mu \mathrm{g}$ of DBP. Two milli-liters of 2-ethylhexanol were added. The vial was then capped (teflon liner) and vortexed for 20 seconds. At an acidic $\mathrm{pH}, \mathrm{DBP}$ is predominately present in the protonated form and will readily transfer to the 2-ethylhexanol organic phase as a function of solubility. The mixture was allowed to settle (about 3 minutes). No stable emulsions were formed. This is due to the anti-foaming characteristics of the 2-ethylhexanol solvent and the ionic strength of the mixture. In the event that a stable emulsion was formed, the addition of 5 drops of $1 \underline{\mathrm{M}}$ nitric acid increases the ionic strength of the solution, thus breaking the emulsion.

The organic phase (top layer) was transferred, via disposable plastic pipette, to another vial containing $5.0 \mathrm{~mL}$ of $1 \mathrm{M} \mathrm{NaOH}$. The vial was capped and vortexed for 20 seconds to backextract DBP. During the back-extraction with NaOH, DBP is deprotonated to DBP- (an anion more soluble in water). After the phases separated, the organic layer was carefully separated from the $\mathrm{NaOH}$ layer and discarded.

Sodium is an interferent ion when analyzing for anions. The ASRS II only suppresses about 0.125 meq of sodium in the recycle mode; therefore, it is necessary to remove the excess sodium from the sample before analyzing it. Three Dionex On-Guard $\mathrm{H}+$ ion exchange cartridges 
were connected in series to remove the 5 meq of sodium from the $\mathrm{NaOH}$ back-extraction. Each On-Guard $\mathrm{H}+$ ion exchange cartridge has a capacity for removing $2-2.5$ meq of sodium, exchanging $\mathrm{H}+{ }^{3}$ The first $3 \mathrm{~mL}$ of the $\mathrm{NaOH}$ back-extract was pushed through the cartridges rather quickly to displace the residual water from rinsing and discarded. The final $2 \mathrm{~mL}$ were filtered drop-wise at rate of $2 \mathrm{~mL} / \mathrm{min}$ and collected in a $5 \mathrm{~mL}$ Dionex autosampler vial. Collection of the filtrate was stopped when the apparent liquid level reached the first cartridge, thus keeping the residual 2-ethylhexanol from passing through the cartridges. The resulting $\mathrm{pH}$ range should be between 3 and 7. If the $\mathrm{pH}$ is 9 or above, the $\mathrm{Na}+$ has not been exchanged adequately.

Standards and recovery studies indicate that this method is quantitative and reproducible for determining the presence of DBP in $\mathrm{H}$-Canyon process material. DBP is effectively extracted and analyzed in a protonated or partially protonated form. Figure 4 is a chromatogram of the $10 \mathrm{ug} / \mathrm{mL}$ calibration verification standard. DBP is calibrated in the neutral $\mathrm{pH}$ range, above the pKa. Figure 4 displays the $10 \mu \mathrm{g} / \mathrm{mL}$ standard analyzed using the improved DBP method.

Figure 4. Chromatogram of $10 \mu \mathrm{g} / \mathrm{mL}$ Standard

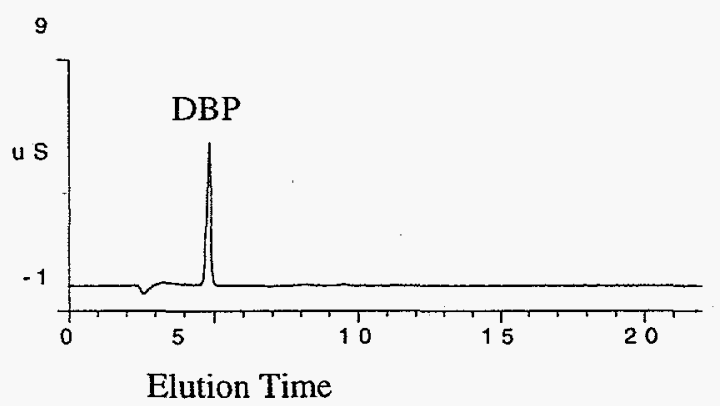

Figure 5 illustrates the $10 \mu \mathrm{g} / \mathrm{mL}$ standard prepared in $0.225 \mathrm{mM}$ Carbonate/Bicarbonate eluent. DBP, as shown, has very little retention on the analytical column and is eluting very close to the water dip as part of the void volume.

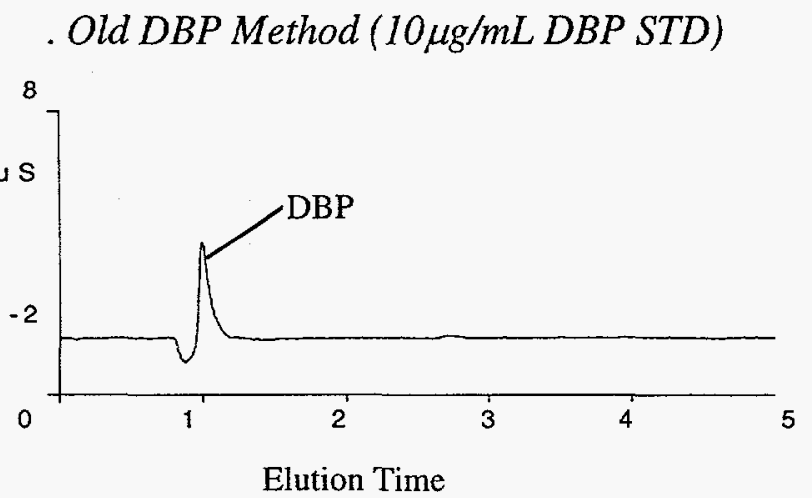

\footnotetext{
${ }^{3}$ Dionex Corporation. Installation Instructions and Troubleshooting Guide for Onguard ${ }^{\mathrm{TM}}$ Cartridges. Document No. 032943, Revision 08, October 17, 1995, On-Guard-H Cartridges.
} 
Figure 6 illustrates the chromatography of DBP from past samples before method improvements were made. A $0.5-1 \mathrm{~mL}$ sample aliquot (in 2-ethyl hexanol) containing DBP in the presence of uranyl-nitrate $\left(\mathrm{UO}_{2}\left(\mathrm{NO}_{3}\right)_{2}\right)$ was partitioned against $0.005 \mathrm{M} \mathrm{NaOH}$. After the solution settled, the bottom layer (slightly yellow) was diluted and injected into the IC system. Low DBP recoveries were observed. As the nitrate concentrations increase, analysis of DBP becomes more and more problematic because of column overloading, thus causing DBP to be retained even less on the analytical column.

\section{Depleted Uranium Sample (pre-method development)}

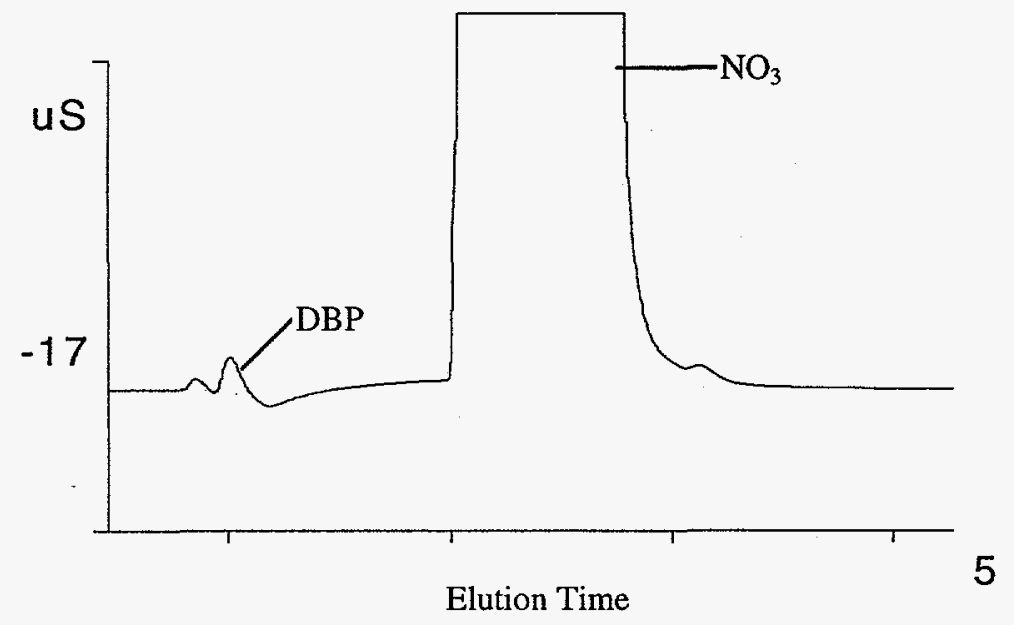

To counter low DBP recovery, DBP had to be isolated from the uranyl species in the form of HDBP and back-extracted in the form of DBP- using $1 \mathrm{M} \mathrm{NaOH}$. After the $\mathrm{Na}$ +interferent was removed and the retention of DBP on the column was increased, this method proved to be accurate and reproducible. Figure 7 displays the chromatography of samples after method improvements. DBP concentration is $33 \mathrm{ug} / \mathrm{mL} \pm 4.4 \%$. The nitrate species eluted in the blank following the sample.

Figure 7. Enriched Uranium Sample. (After Method Improvements)

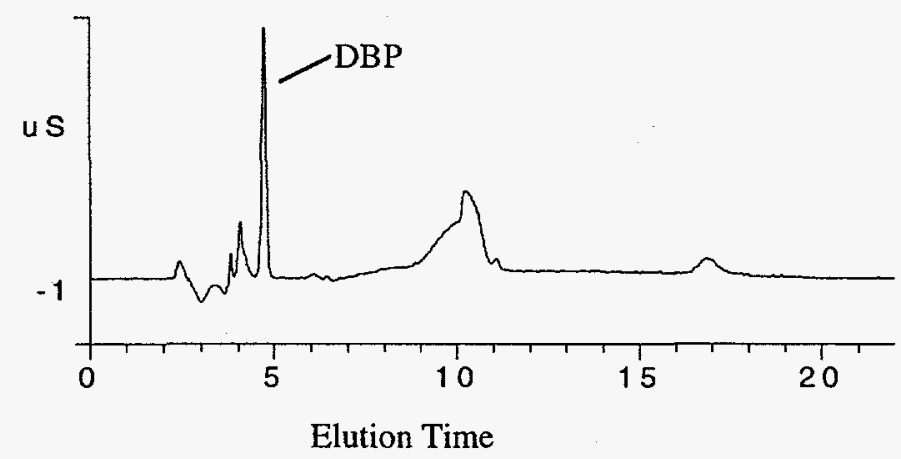

Method detection limit (MDL) studies were performed using the $15 \mathrm{~g} / \mathrm{L}$ uranium- $0.15 \underline{\mathrm{M}}$ nitric acid matrix material. A $1 \mathrm{~mL}$ aliquot of the matrix material was added to a $22 \mathrm{~mL}$ glass vial 
containing $5 \mathrm{~mL}$ of reagent water. The solution was spiked with $10 \mu \mathrm{g}$ of DBP $(0.04 \mu \mathrm{g}$ on column) and carried through the rest of the extraction/back-extraction procedure. The average recovery was $108 \%$. The MDL value for seven replicates was $1.55 \mu \mathrm{g} / \mathrm{mL}$ using a t-statistic value of 3.14. The results for the MDL study is shown in Figure 8. Figure 9 is a chromatogram of the MDL matrix spike.

Figure 8. Method Detection Limit Study

\begin{tabular}{|c|c|c|c|c|c|c|c|}
\hline & $\begin{array}{c}\text { Trial } \\
\# 1\end{array}$ & $\begin{array}{c}\text { Trial } \\
\# 2 \\
\end{array}$ & $\begin{array}{c}\text { Trial } \\
\# 3 \\
\end{array}$ & $\begin{array}{c}\text { Trial } \\
\# 4\end{array}$ & $\begin{array}{c}\text { Trial } \\
\# 5 \\
\end{array}$ & $\begin{array}{c}\text { Trial } \\
\# 6\end{array}$ & $\begin{array}{c}\text { Trial } \\
\# 7 \\
7\end{array}$ \\
\hline \%Recovery & 108 & 107 & 104 & 105 & 114 & 102 & 115 \\
\hline $\begin{array}{l}\text { Average } \\
\text { Recovery }\end{array}$ & $108 \%$ & & & & & & \\
\hline $\begin{array}{l}\text { Standard } \\
\text { Deviation }\end{array}$ & 0.495 & & & & & & \\
\hline $\begin{array}{l}\text { MDL } \\
\text { Value }\end{array}$ & 1.55 & & & & & & \\
\hline
\end{tabular}

Figure 9. Chromatogram of MDL Spike

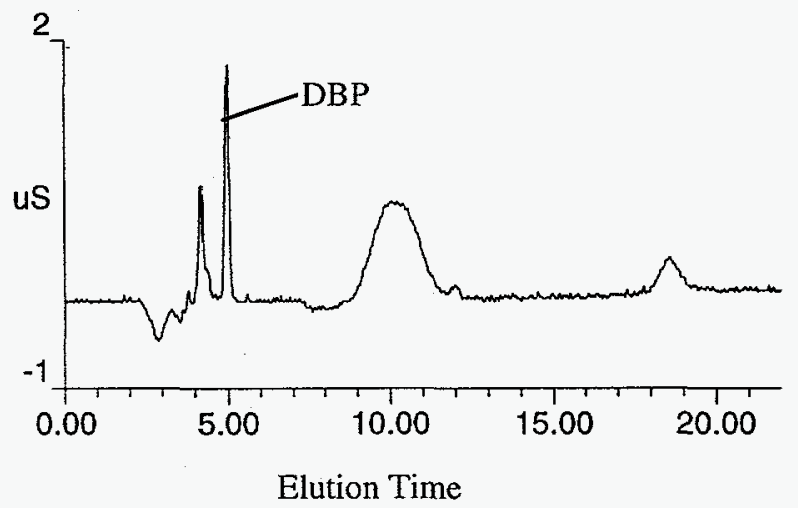

The accuracy/precision study was carried out in the same manner except the spiked amount of DBP was increased to $100 \mu \mathrm{g}$ into solution $(0.4 \mu \mathrm{g}$ on column). An average recovery of $76 \%$ was observed. The results for the Accuracy/Precision study is shown in Figure 11. Figure 12 is a chromatogram of the accuracy/precision Spike. The method uncertainty value was calculated to be $\pm 4.4 \%$. This uncertainty value was taken from the $\%$ RSD and represents the total error for this analysis. 
Figure 10. Accuracy/Precision Study

\begin{tabular}{|c|c|c|c|c|}
\hline & $\begin{array}{c}\text { Trial } \\
\# 1\end{array}$ & $\begin{array}{c}\text { Trial } \\
\# 2 \\
\end{array}$ & $\begin{array}{c}\text { Trial } \\
\# 3 \\
\end{array}$ & $\begin{array}{c}\text { Trial } \\
\# 4 \\
\end{array}$ \\
\hline \%Recovery & 73 & 73 & 76 & 80 \\
\hline $\begin{array}{l}\text { Average } \\
\text { Recovery }\end{array}$ & $76 \%$ & & & \\
\hline $\begin{array}{l}\text { Standard } \\
\text { Deviation }\end{array}$ & 3.317 & & & \\
\hline \%RSD & 4.4 & & & \\
\hline
\end{tabular}

Figure1 1. Chromatogram of Accuracy/Precision Matrix Spike

9

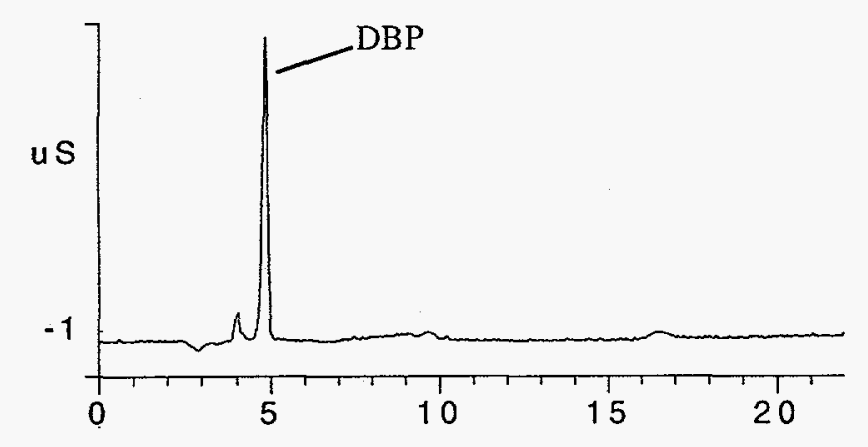

Elution Time

\section{Conclusions}

Analysis of DBP by Ion Chromatography is an accurate and precise method. Analytical problems encountered from past analyses have been addressed and corrected. Data Uncertainties have been decreased from over $\pm 25 \%$ to $\pm 4.4 \%$.

Analytical results by this method have proven to be consistent and reproducible. It is advised that a matrix spike and a matrix spike duplicate be analyzed per sample batch, per matrix type to assess analte recoveries. Based upon the accuracy and precision of this method, analytical values can be adjusted to account for DBP recovery. This adjustment is closer to the true value with $\mathrm{a} \pm 4.4 \%$ Uncertainty.

The calibration curve should range from $0.2 \mu \mathrm{g}$ to $2 \mu \mathrm{g}$ of DBP on column. Samples with less than $0.2 \mu \mathrm{g}$ of DBP on column will be in a different response range of the conductivity detector as demonstrated in Figure 2. However, linearity does exist between $0.04 \mu \mathrm{g}$ and $0.2 \mu \mathrm{g}$ DBP on-column. Therefore, the response factor for $0.2 \mu \mathrm{g}$ may by used to quantify samples containing between $0.04 \mu \mathrm{g}$ and $0.2 \mu \mathrm{g}$ of DBP on column. Alternatively, the sample size may be increased. 


\section{References}

1. R.A. Pierce, M.C. Thompson, R.J. Ray. "Solubility Limits of Dibutyl Phosphoric Acid in Uranium Solutions at SRS (U)", WSRC-TR-98-00188, Rev. 0.

2. K.E. Grant, G.M. Mong, S.A. Clauss, K.L. Wahl, J.A. Campbell. "Determination of Monobutyl Phosphate and Dibutyl Phosphate in Mixed Hazardous Wastes by Ion-Pair Chromatography", Journal of Radioanalytical and Nuclear Chemistry, Vol. 220, No. 1 (1997) 31-35.

3. EPA, 1990, "Test Methods for Evaluating Solid Wastes, Physical/Chemical Methods", SW846, Revision 1, U.S. Environmental Protection Agency, Washington, D.C. 